\title{
Selective growth and mortality of juvenile 0-group plaice Pleuronectes platessa in the Dutch Wadden Sea: a consequence of irreversible non-genetic adaptation during early pelagic life
}

\author{
Henk W. van der Veer*, Barry Bies, Johannes IJ. Witte \\ Netherlands Institute for Sea Research (NIOZ), PO Box 59, 1790 AB Den Burg Texel, The Netherlands
}

\begin{abstract}
In this paper, we have addressed the question of whether selective growth and mortality of juvenile 0-group plaice Pleuronectes platessa (L.) occurs in the Dutch Wadden Sea as a consequence of irreversible non-genetic adaptation to water temperature conditions during early pelagic life. As tracers, the number of vertebrae, and of dorsal and anal fin rays were used, since the variability in these characteristics reflects the phenotypic plasticity induced by differences in environmental conditions, and especially water temperature, during early pelagic life. From the onset of larval immigration in March 1995, the juvenile 0-group plaice population was sampled frequently and the variability in its meristic characteristics was analysed. The number of vertebrae appeared to be established by water temperature conditions during the egg stage, while the number of dorsal and anal fin rays seemed to be determined during the larval stage. As a consequence, the number of vertebrae was not correlated with either the number of dorsal fin rays or the number of anal fin rays, but the numbers of anal fin rays and dorsal fin rays were strongly correlated. Strong support was found for Kinne's (1962; Comp Biochem Physiol 5:265-282) 'irreversible non-genetic adaptation' hypothesis - that the variability induced by environmental conditions during early life still expresses itself later on in juvenile life-as there was a significant positive relationship in our study between growth and the number of vertebrae during the period April to July. Also, instantaneous mortality was positively related to the number of vertebrae. It is suggested that the relationship with mortality results from a correlation between vertebral number and some important characteristic involved in avoiding predators, such as locomotory performance. Also, mean growth rate during the growing season and instantaneous mortality rate were positively correlated for each meristic characteristic. It is argued that the relationship between growth and mortality will vary over the years and will depend on the combination of environmental conditions during egg and larval stage compared to those during the subsequent juvenile stage.
\end{abstract}

KEY WORDS: Juvenile $\cdot$ Growth $\cdot$ Mortality $\cdot$ Non-genetic adaptation hypothesis $\cdot$ Plaice $\cdot$ Phenotypic plasticity $\cdot$ Selection $\cdot$ Pleuronectes platessa

\section{INTRODUCTION}

Individual fish can be characterised by-among other factors - their serial repeated structures, such as number of vertebrae and fin rays. The number of these various meristic parts is fixed during ontogeny, and remains unchanged during the subsequent juvenile

•E-mail: veer@nioz.nl and adult life stage of the fish. Environmental conditions during early development have a clear influence and modify the number of these meristic parts, and especially temperature conditions appear to be of importance (for review see Lindsey 1988). Therefore, the observed variability in the meristic characteristics of a population, during the juvenile stage as least, will reflect partly the phenotypic plasticity induced by differences in environmental conditions during early pelagic life, and especially temperature. The conse- 

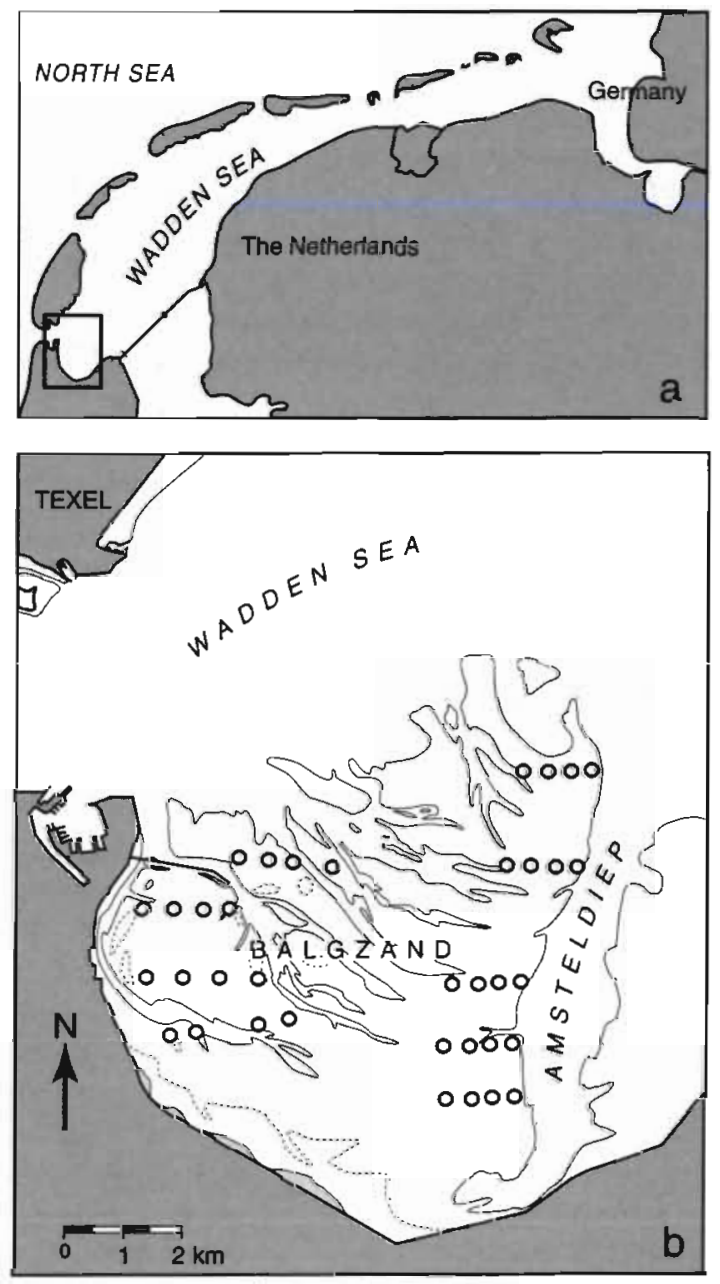

Fig. 1. The western Dutch Wadden Sea (a), with location of the Balgzand tidal flat area (b) and flatfish sampling stations (o)

quences of such meristic differences between individuals is still rather unclear (Lindsey 1988). However, in 1962 Kinne published his seminal paper on irreversible non-genetic adaptation, in which he demonstrated that changes in the (osmotic) environment of fish eggs of Cyprinodon macularius experienced shortly after oviposition induced functional non-genetic adaptation, which was not reversible during the subsequent life of the individual. This, at least, suggests that meristic differences induced by the variability in environmental conditions during early life might still express itself on a functional level, such as growth, later on in life.

One of the main spawning areas for plaice Pleuronectes platessa is located in the Southern Bight of the North Sea. Once released in January-February, the developing eggs and larvae are transported by residual currents towards nursery areas along the Dutch and German coast (Simpson 1959, Harding \& Talbot 1973, Talbot 1976, 1978, Harding et al. 1978). In these nurseries, the larvae settle and transfer to a demersal way of life (Creutzberg et al. 1978). Over the period of spawning and between years, the median developmental temperature during egg and larval drift varies between 6 and $10^{\circ} \mathrm{C}$ (Van der Veer \& Witte 1999) and these differences will induce variability in meristic characteristics, as has been documented for plaice by Tåning (1944) and Molander \& Molander-Swedmark (1957). It has been suggested that the number of vertebrae appears to be related to the environmental temperature of the eggs, while the environmental temperature of the larvae determines the numbers of fin rays (Hiddink 1997). In case of non-genetic adaptation, these temperature differences during development will still express themselves later on in life on a functional level, which implies that after settlement each individual fish will grow best at temperatures near the temperature at which it passes its own embryonic development. As a consequence, different temperature optima for growth of juvenile plaice in the nurseries can be expected for individual fish and for the various different meristic groups. Since mortality among settled juvenile plaice is strongly size-dependent (Van der Veer \& Bergman 1987, Ellis 1994, Van der Veer et al. 1997), differences in growth might subsequently also imply differences in mortality.

In this paper, we have addressed the question of whether selective growth and mortality of juvenile 0-group plaice occurs in the Dutch Wadden Sea as a consequence of irreversible non-genetic adaptation during early pelagic life. From the onset of larval immigration in March 1995, the juvenile 0-group plaice population was sampled frequently and the variability in its meristic characteristics was analysed. For each sampling the plaice population was split up into various subgroups and, subsequently, growth and mortality were estimated and followed for each subgroup during the season. As tracers, the number of vertebrae and number of dorsal and anal fin rays were used.

\section{MATERIAL AND METHODS}

Sampling. 0-group flatfish sampling was carried out at the Balgzand, a large isolated tidal flat system in the western Wadden Sea, in 1995 (Fig. 1). Fishing was done identically to previous sampling in the area (Zijlstra et al. 1982, Van der Veer 1986, Van der Veer \& Witte 1999). Briefly, a grid of 36 stations distributed over the area was sampled at frequent intervals (2 to 4 wk) from March until August. Fishing was carried out during a period of $1.5 \mathrm{~h}$ around high water, since during this period juvenile flatfish are distributed randomly over the area (Kuipers 1973). Hauls of about $100 \mathrm{~m}$ in length were made during the daytime using a 
$1.9 \mathrm{~m}$ beam trawl with 1 tickler chain and a mesh size of $5 \times 5 \mathrm{~mm}$, towed by a rubber dinghy with a $25 \mathrm{HP}$ outboard motor at a speed of approximately $35 \mathrm{~m} \mathrm{~min}^{-1}$ (Riley \& Corlett 1966). Location of the hauls was established by GPS and the length of the hauls was assessed with a meter-wheel fitted outside the trawl. Catches were deep-frozen and sorted out within a few days in the laboratory. All 0-group plaice were preserved in $70 \%$ ethanol and all fish were measured to the nearest mm TL, without a correction for shrinkage. Numbers caught were corrected for size-selective mesh and catch efficiency after Kuipers (1975) and Dapper (1978) and converted into numbers per $1000 \mathrm{~m}^{2}$ [ind. $\left.\left(10^{3} \mathrm{~m}^{2}\right)^{-1}\right]$. The arithmetic mean of all stations sampled during a survey was calculated as an index of abundance for the randomly distributed population of the whole area at high water. For more information see Zijlstra et al. (1982) and Van der Veer (1986).

Meristic characteristics. From each cruise, 0-group plaice were split into just-settled larvae $(\leq 15 \mathrm{~mm})$ and post-settled plaice (>15 mm). Settling larvae were divided into $\mathrm{mm}$ length-classes and post-settled plaice were divided into $5 \mathrm{~mm}$ length-classes. From each length-class, maximum 25 individuals were selected at random from the various hauls. After rinsing with $1 \%$ $\mathrm{NaCl}$, the fish were bleached individually in a $1 \%$ $\mathrm{NaCl}, 0.45 \% \mathrm{H}_{2} \mathrm{O}_{2}$ and $0.85 \% \mathrm{KOH}$ solution for 20 to 60 min depending on their size (Potthoff 1983). The fish were then kept overnight in $1 \% \mathrm{KOH}$ for maceration. Next day the fish skeletons were stained with an alizarin red solution for about $3 \alpha$. Finally, after rinsing with a $1 \% \mathrm{NaCl}, 0.5 \% \mathrm{KOH}$ solution, the fish were stored and cleared in a solution consisting of $50 \%$ glycerine and $50 \%$ of $0.5 \% \mathrm{KOH}_{1} 1 \% \mathrm{NaCl}$. All the dilutions were made with demineralized water.

For each individual, the number of vertebrae, dorsal fin rays and anal fin rays was counted. No further attention was paid to other morphometric characteristics. Counting was done by means of a dissecting microscope. Sometimes fish bigger than $25 \mathrm{~mm}$ had not become clear enough for counting, in which case the unpigmented side was removed. In this way the stain could penetrate more easily and the bony structures became more visible.

Counting of the vertebrae started at the first vertebra attached to the skull (see Fig. 2). This vertebra was always accompanied by a thin haemal arch that made an angle with the second haemal arch which was attached to the second vertebra. From this point the vertebrae were called 'abdominal vertebrae'. The second characteristic feature was the first caudal vertebra that always had a long and curved neural arch. Beyond this point the vertebrae were marked as 'caudal'. The last mark of recognition was the urostyle, a distinguishable vertebra with an upward protuber- ance. This vertebra was regarded as the last one. If enlarged and fused vertebrae were found, they were treated as indicated in Fig. 2.

Often the fish were damaged so that some fin rays were partly lost. In this case the notches in which they would have been embedded were counted. In some cases fin rays were missing. If possible these missing fin rays were completely estimated from the underlying ray bearers (usually there was 1 fin ray between 2 ray bearers); otherwise they were left out of the analysis.

Statistical analysis. For each cruise and each sizeclass the fractions of the various numbers of vertebrae, dorsal fin rays and anal fin rays were determined and subsequently multiplied by the density of that sizeclass. These fractions were converted into numbers per $1000 \mathrm{~m}^{2}$ per length-class. Subsequently, for each morphometric characteristic the total size frequency distribution and total number of individuals per $1000 \mathrm{~m}^{2}$ per cruise were estimated. For each characteristic, growth and mortality during the growing season were determined.
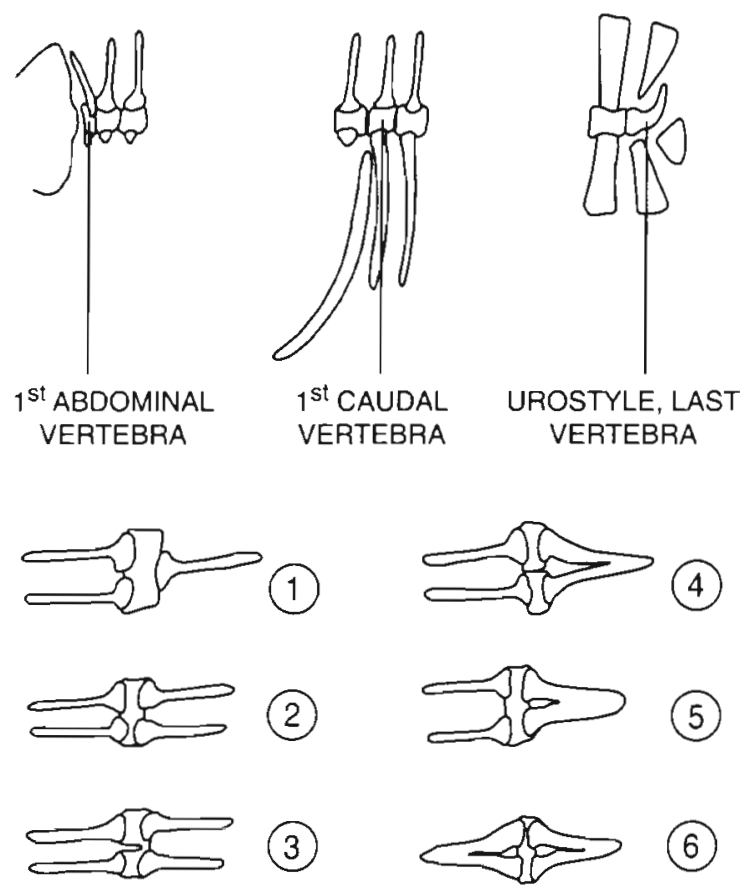

Fig. 2. Classification of the various types of cryptic (=enlarged and fused) vertebrae: Type (1); 1 extended vertebra with 2 haemal arches and one neural arch. Counted as 1 vertebra Type (2); 1 extended vertebra with 2 neural as well as 2 haemal arches. Counted as 1 vertebra. Type (3); 2 (partly) fused vertebrae with 2 neural as well as 2 haemal arches. Counted as 2 vertebrae. Type (4); 2 vertebrae with 2 fused haemal arches and 2 seperated neural arches. Counted as 2 vertebrae. Type (5); 1 extended vertebra with 2 fused haemal arches and 2 seperated neural arches. Counted as 1 vertebra. Type (6); 1 extended vertebra with 2 fused haemal arches and 2 fused neural arches. Counted as 1 vertebra 


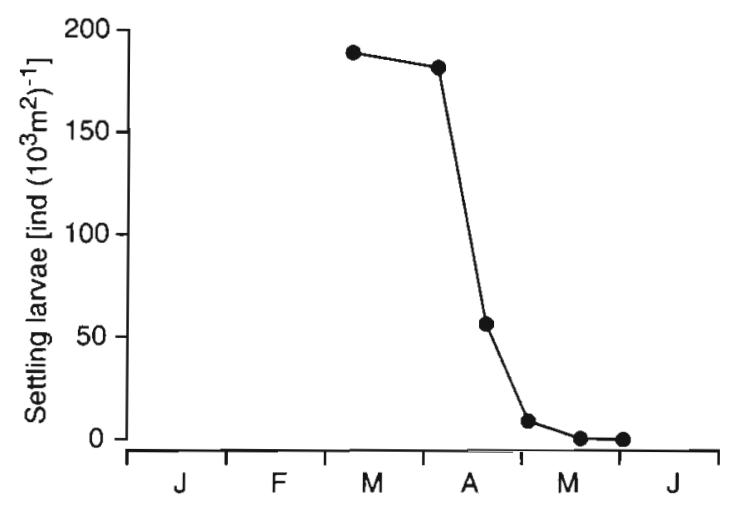

Fig. 3. Pleuronectes platessa. Pattern of settling plaice larvae [ind. $\left(10^{3} \mathrm{~m}^{2}\right)^{-1}$ ], defined as all individuals $\leq 15 \mathrm{~mm}$ according to Van der Veer (1986), at the Balgzand in 1995

Daily instantaneous mortality $\left(M, \mathrm{~d}^{-1}\right)$ was estimated for the various subpopulations of each meristic characteristic by linear regression according to the following model:

$$
\operatorname{Ln}\left(N_{i}\right)=a_{j}+M_{i} \cdot \operatorname{DAY}
$$

in which $N_{i}=$ density of a specific subgroup; $a_{i}=$ constant DAY $=$ the Julian day number, $M_{i}=$ the daily instantaneous mortality rate; and $i$ refers to a specific subgroup (for instance all individuals with 41 vertebrae). Significant differences between subgroups were analysed using the following model:

$$
\operatorname{Ln}(N)=a+M \cdot \mathrm{DAY}+\mathrm{MER}+\mathrm{MER} \cdot \mathrm{DAY}
$$

in which MER = the meristic subgroup. Significant differences in $M$ between subgroups will be reflected in a significant contribution of the interaction term MER . DAY.

Growth was analysed by following the increase in mean total length $(M L, \mathrm{~mm})$ of the various groups. Pre-

vertebrae $\square$ anal fin rays $\square$ dorsal fin rays

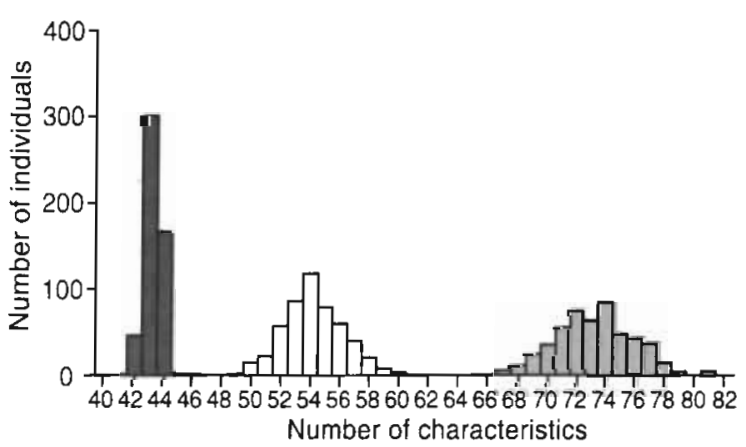

Fig. 4. Pleuronectes platessa. Total frequency distribution (n) of the various meristic characteristics (vertebrae, anal fins, dorsal fins) of settling plaice at the Balgzand over the period of immigration in 1995 vious research (Van der Veer 1986) showed that the increase in mean length during the growing season did not differ significantly from linear growth. Therefore, growth and differences in growth between the various subgroups were analysed according to the same models as those used for the analysis of daily mortality:

$$
\begin{gathered}
M L_{i}=a_{i}+G R_{i} \cdot \mathrm{DAY} \\
M L=a+G R \cdot \mathrm{DAY}+\mathrm{MER}+\mathrm{MER} \cdot \mathrm{DAY}
\end{gathered}
$$

in which $G R_{j}$ is the growth rate ( $m \mathrm{~d} \mathrm{~d}^{-1}$ ) and $i$ refers to a specific subgroup. All tests were performed by SYSTAT (Wilkinson 1989).

\section{RESULTS}

\section{Settling larvae}

Larval immigration (individuals $\leq 15 \mathrm{~mm}$ TL) in 1995 had already started at the beginning of March and continued until the middle of May (Fig. 3). Maximum numbers were observed from mid-March to mid-April, of about 200 ind. $\left(10^{3} \mathrm{~m}^{2}\right)^{-1}$. A total of 518 settling larvae were analysed for meristic characteristics (Fig. 4). The range in number of vertebrae was small, from 40 to 45 . Individuals with 43 vertebrae were most abundant, followed by larvae with 44 and 42 vertebrae respectively. In anal fin rays, a larger range was observed, from 47 to 68 rays. The frequency distributions did not differ significantly from a normal distribution, which was also reflected in the fact that mean and median were about the same, 54 fin rays. The range in dorsal fin rays was from 65 to 83 rays, and the frequency distribution did not differ significantly from a normal distribution either. Mean and median were about 73 fin rays. In all analyses and figures the groups of the different number of dorsal fin rays are pooled two by two. For instance, group 66 refers to all individuals with 66 and 67 dorsal fin rays, the group 68 refers to 68 and 69 , etc. On an individual basis, the number of vertebrae was not correlated with either the number of anal fin rays or the number of dorsal fin rays, but the number of anal fin rays and the number of dorsal fin rays were strongly correlated (Table 1). The relative

Table 1. Correlations between the various meristic characteristics $\left(R^{2}\right)$ of immigrating plaice larvae at the Balgzand in 1995. No. of ind.: 520

\begin{tabular}{|lcc|}
\hline & $\begin{array}{c}\text { No. of } \\
\text { vertebrae }\end{array}$ & $\begin{array}{c}\text { No. of } \\
\text { anal fin rays }\end{array}$ \\
\hline No. of anal fin rays & 0.18 & \\
No. of dorsal fin rays & 0.18 & 0.69 \\
\hline
\end{tabular}


contribution of the various characteristics did not differ during the period of immigration $\left(\chi^{2}\right.$-test; $\left.p<0.01\right)$, although some variation did occur among weeks (Fig. 5).

\section{Post-settled plaice}

The seasonal abundance of the various subpopulations showed a similar pattern for each meristic characteristic (Fig. 6). Maximum densities could be observed in April-May and thereafter decreasing densities occurred until about July. During this period, mean length of the various subgroups increased from about $15 \mathrm{~mm}$ at the end of March, until a mean length between 45 and $75 \mathrm{~mm}$ was reached at the end of June, depending on the meristic characteristic (Fig. 7).

Daily instantaneous mortality $\left(M_{1} \mathrm{~d}^{-1}\right)$ was estimated for the various subpopulations of each meristic for vertebrae, anal fin rays and dorsal fin rays (Table 2 ). In the case of vertebrae, the interaction term was not significant (ANOVA, $p>0.05$ ), which means that there were no significant differences in mortality between subgroups. Nevertheless, there was a significantly positive correlation between number of vertebrae and instantaneous mortality rate (Spearman's rank correlation $r_{s}=0.90, p<0.05$ ) (Fig. 8). For anal fin rays and dorsal fin rays, the interaction term significantly contributed (ANOVA, $p<0.05$ ), which means that significant differences were present in mortality rates between the various subgroups (Fig. 8). Both for anal fin rays and dorsal fin, a significantly positive correlation between number of meristic characteristics and instantaneous mortality rate was also found $\left(r_{s}=0.56\right.$, $p<0.05 ; r_{s}=0.96, p<0.05$ respectively for anal fin rays and dorsal fin rays).

With respect to the growth estimates (Table 2), the interaction term significantly contributed in the case of vertebrae (ANOVA, $p<0.05$ ), which means that there were significant differences between subgroups. These differences in growth between subgroups were positively correlated with the number of vertebrae $\left(\mathrm{r}_{\mathrm{s}}=\right.$ $1.00, p<0.05$ ) (Fig. 9). The interaction term was not significant for either anal fin or dorsal fin rays, (ANOVA, $\mathrm{p}>0.05$ ). There was also no significant (ns) relationship between the growth rate of a subgroup and the number of a characteristic $\left(\mathrm{r}_{\mathrm{s}}=0.42, \mathrm{~ns} ; \mathrm{r}_{\mathrm{s}}=\right.$ 0.20 , ns respectively for anal and dorsal fin rays).

Mean growth rate during the growing season and instantaneous mortality rate were positively correlated for each of the 3 meristic characteristics (Fig. 10). In case of vertebrae, this correlation was significant $\left(I_{\mathrm{s}}=\right.$ $0.97 ; n=5 ; p<0.05$ ), whereas for anal fin rays and dorsal fin rays the correlation was not $\left(r_{\mathrm{s}}=0.53, n s ; r_{\mathrm{s}}=\right.$ 0.47 , ns respectively).
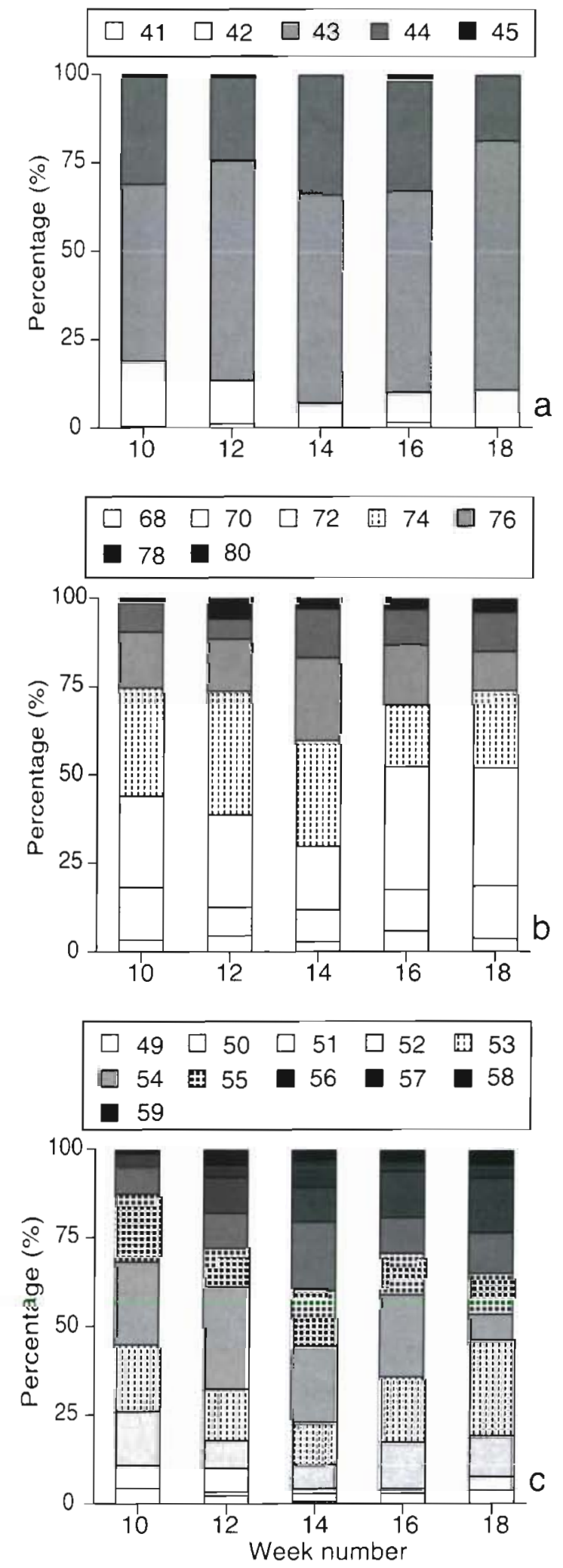

Fig. 5. Pleuronectes platessa. Frequency distribution (\%) of the various meristic characteristics of settling plaice during the period of immigration at the Balgzand in 1995. (a) Vertebrae $_{\text {(b) dorsal fin rays; (c) anal fin rays }}$ 

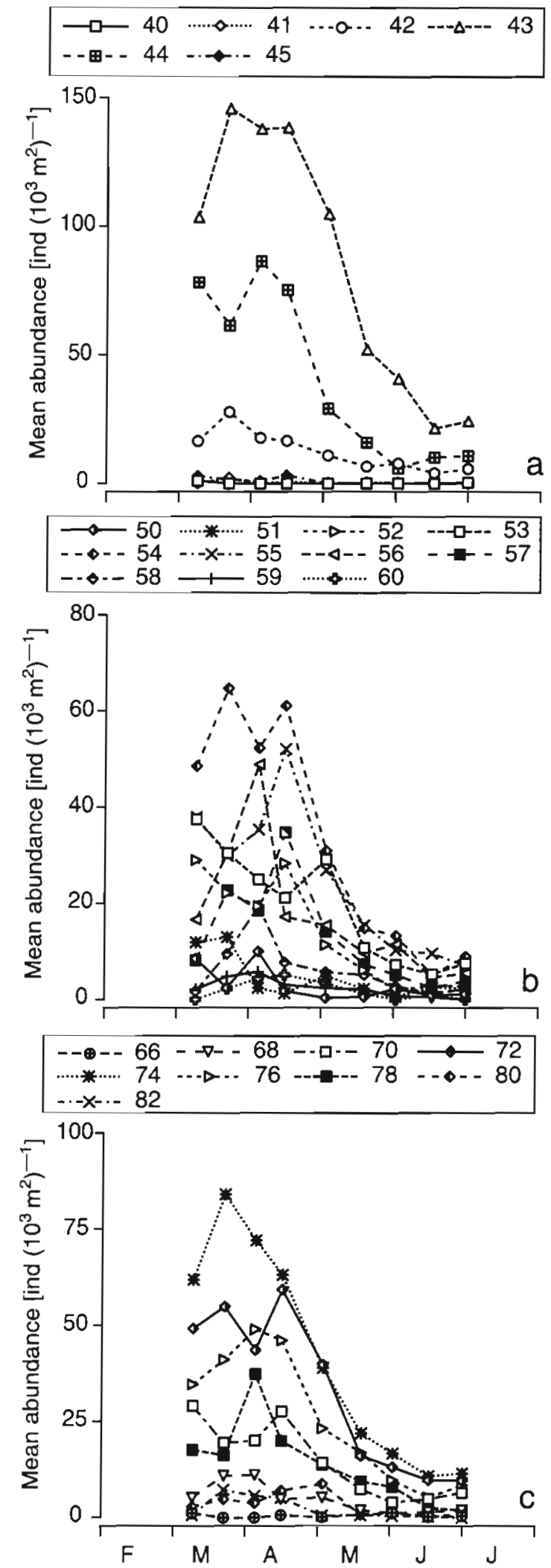

Fig. 6. Pleuronectes platessa. Seasonal pattern of mean abundance [ind. $\left.\left(10^{3} \mathrm{~m}^{2}\right)^{-1}\right]$ of the various meristic subpopulations of 0-group plaice at the Balgzand in 1995. (a) Vertebrae; (b) anal fin rays; (c) dorsal fin rays

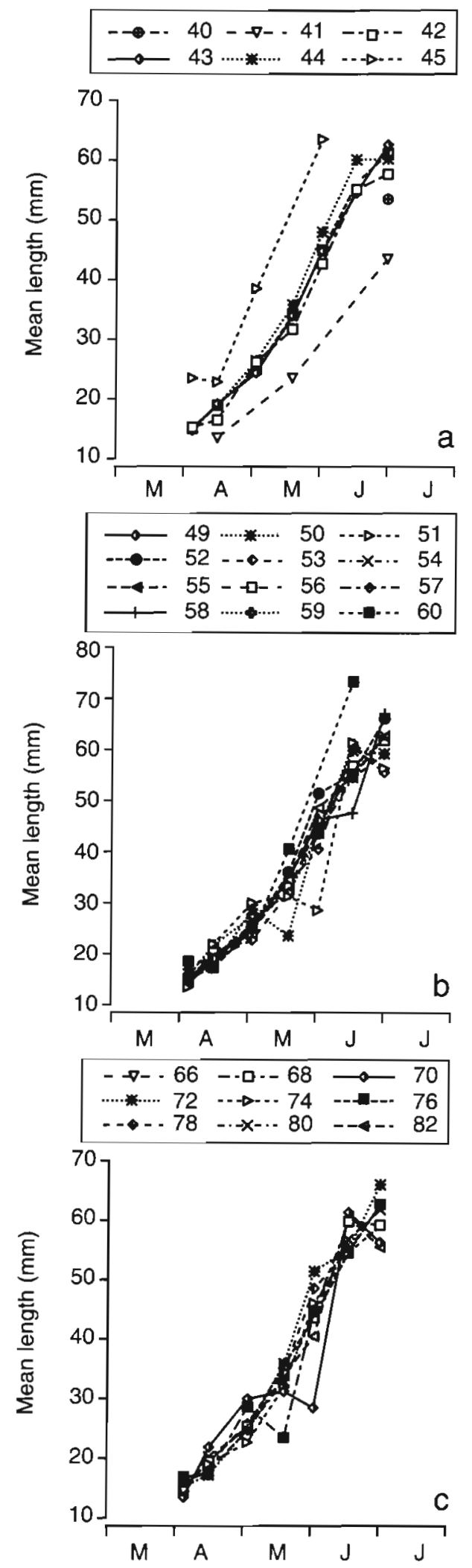

Fig. 7. Pleuronectes platessa. Seasonal pattern of mean length $(\mathrm{mm})$ of the various meristic subpopulations of 0-group plaice at the Balgzand in 1995. (a) Vertebrae; (b) anal fin rays; (c) dorsal fin rays 
Table 2. Daily instantaneous mortality $\left(M, \mathrm{~d}^{-1}\right)$ and daily growth $\left(G R, \mathrm{~mm} \mathrm{~d}^{-1}\right)$ estimates together with associated statistics for the various meristic characteristics (subpopulations) of 0-group plaice at Balgzand in 1995. For more information and the models used see text

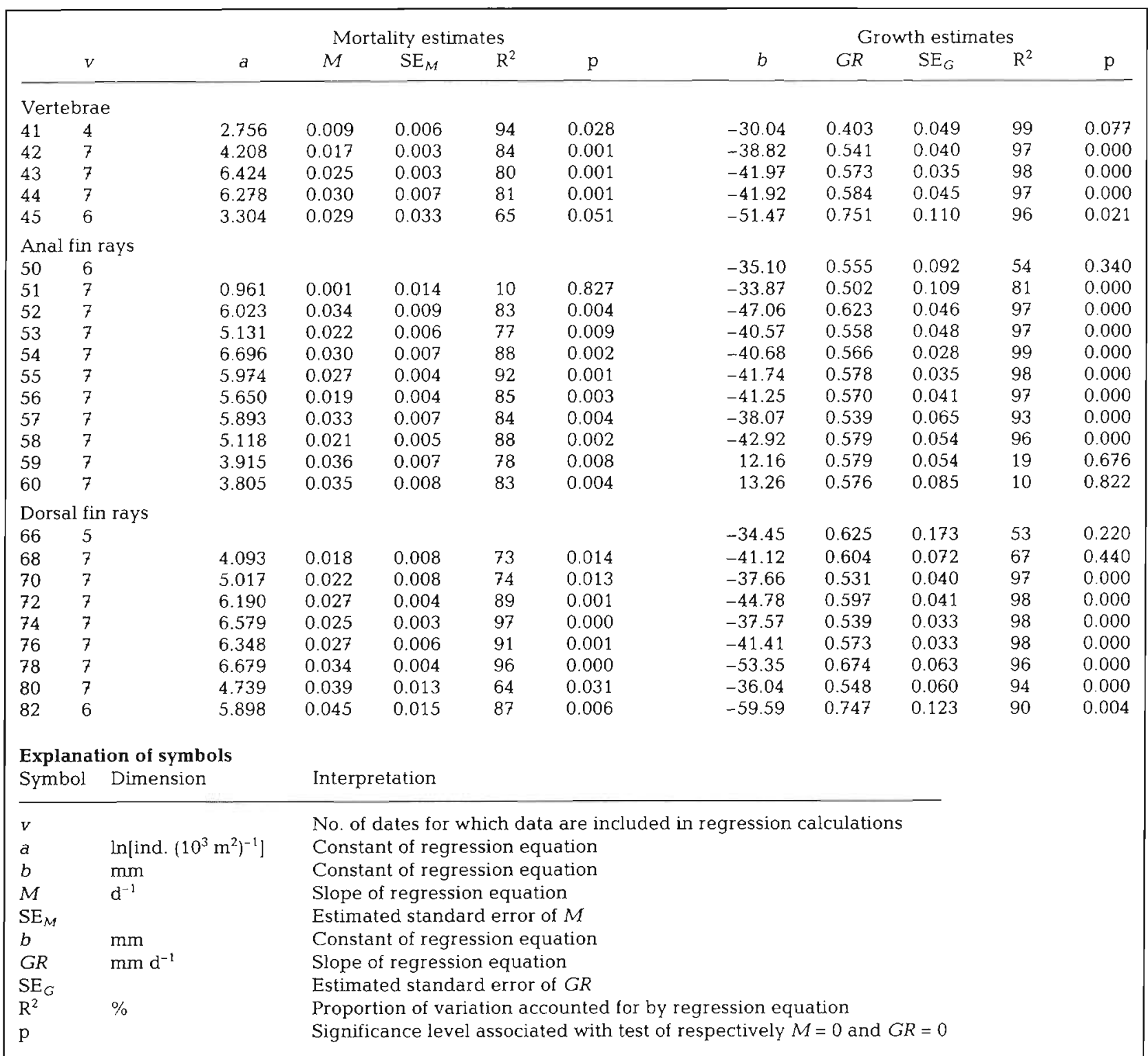

\section{DISCUSSION}

\section{Early life history and meristic variability}

Although a substantial amount of experimental research has made it clear that variability in meristic characteristics in fish is generated by variability in environmental conditions during early life, the underlying mechanisms are still unclear and under debate (Lindsey 1988). Various factors are known to affect the variability in meristic characteristics; however the most important one is temperature during development. In plaice, experimental work suggests that the various characteristics might even be determined during different periods in early life. According to Molander \& Molander-Swedmark (1957), the number of fin rays is determined later during development than the number of vertebrae. Recently, Hiddink (1997) demonstrated that the number of vertebrae is determined during the egg stage, and the number of fin rays seems to be determined during the subsequent larval stage. Our field work on the settling plaice larvae at Balgzand supports this view: the number of vertebrae was not correlated with either the number of anal fin rays or 

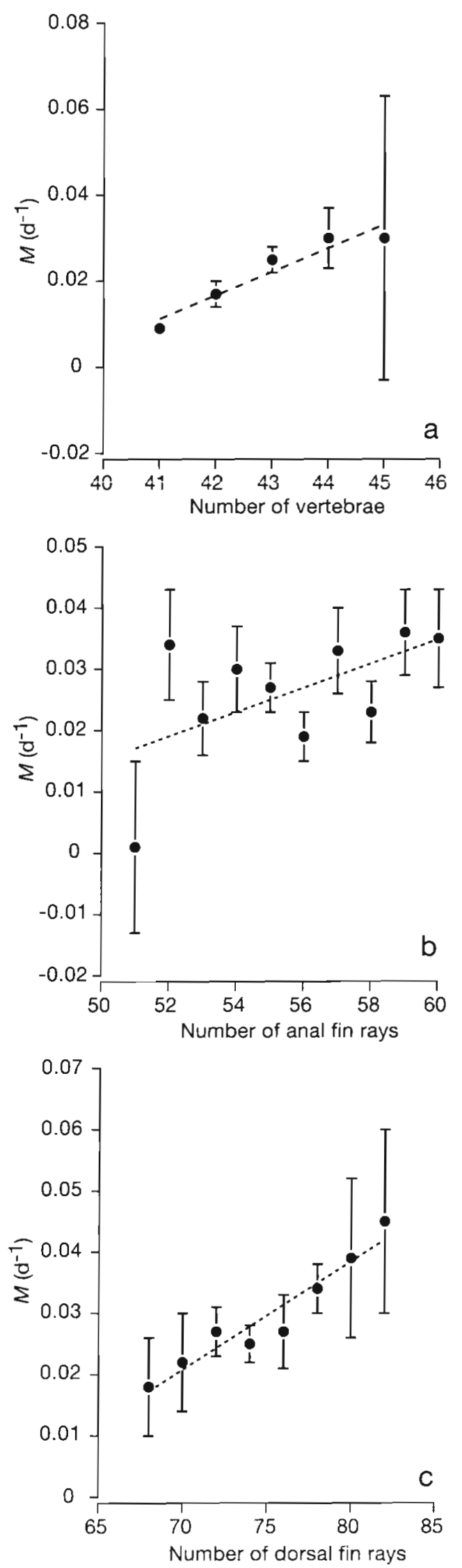

the number of dorsal fin rays, while the number of anal fin rays and the number of dorsal fin rays were strongly correlated.

The response patterns of the various meristic counts to the sustained developmental temperature appear to differ in plaice (Dannevig 1950, Molander \& MolanderSwedmark 1957). The mean number of vertebrae shows a $V$-shape response to developmental temperature, with a minimum at about $8^{\circ} \mathrm{C}$, while the response for the mean number of dorsal and anal fin rays is a positive one. In the period of egg and larval drift, no stratification in the Southern Bight occurs, and hence NOAA sea surface satellite images can be used to obtain accurate estimates of the temperatures in the water column experienced during drift (Van der Veer \& Witte 1999). Temperature conditions in 1995 differed from those in other years (Van der Veer \& Witte 1999). Water temperature in 1995 was relatively high, about 8 to $10^{\circ} \mathrm{C}$, and fairly constant compared with other years. This means that in 1995 the general V-shaped response pattern of the number of vertebrae with temperature will have been reduced to a positive one over the temperature range of 8 to $10^{\circ} \mathrm{C}$. In 1995, the immigrating plaice larvae also showed a quite constant pattern of meristic characteristics during the period of immigration in March and April as a consequence of the fairly constant temperatures during the period of egg and larval drift in spring. The number of vertebrae of the immigrating larvae corresponded with those found by Molander \& Molander-Swedmark (1957) for plaice originating from a higher latitude. However, the numbers of dorsal and anal fin rays of the immigrating larvae were about 4 fin rays more than those found by Molander \& Molander-Swedmark (1957).

\section{Selective growth and mortality?}

The significant differences in population growth between the various meristic subgroups might imply that the variability induced by environmental conditions during early life-as reflected in meristic differences-still expresses itself later on in life, or it might be a bias and a sole reflection of size-selective mortality. Growth and mortality are strongly interrelated: size-selective mortality will affect the size distribution of the population and hence the apparent population growth. Negative size-selective predation (relatively

Fig. 8. Pleuronectes platessa. Relationship between number of meristic characteristics and mean instantaneous mortality rate $\left(M, \mathrm{~d}^{-1}\right)$ during the period mid April to the end of June for the various subgroups of 0-group plaice at Balgzand in 1995. (a) Vertebrae; (b) anal fin rays; (c) dorsal fin rays. For more information see text 
removing the smallest individuals) will increase the apparent population growth rate, while on the other hand positive size-selective predation (relatively removing the largest individuals) will reduce the population growth rate. So, whether the observed positive relationship between population growth and mortality is realistic, or whether it is a bias, depends in particular on the presence or absence of negative size-selective mortality.

Negative size-selective predation does operate in 0 group plaice up to a size of $30 \mathrm{~mm}$ and is caused by predation by the brown shrimp Crangon crangon (Van der Veer \& Bergman 1987, Van der Veer et al. 1997). This predation by shrimps occurs directly after settlement until about the beginning of May. This period hardly corresponds with the observed size range and period of selective growth and mortality in 0-group plaice up to the end of June with an increase in mean total length from about 25 to $60 \mathrm{~mm}$. It suggests that the observed differences in population growth cannot be caused by negative size-selective predation by shrimps. The main mortality factor operating from May onwards is predation, first by another crustacean, the shore crab Carcinus maenas (Van der Veer \& Bergman 1987), and later on by fishes, especially gadoids (Van der Veer et al. 1997). Shore crabs are able to consume 0 -group plaice up to about $5 \mathrm{~cm}$, and gadoids are able to prey upon larger plaice. Until the end of June, plaice will pass through this period of shore crab predation. As the plaice enter this prey field of the shore crabs, predation will first be concentrated on the largest individuals (positively size-selective). Later on when the plaice outgrow the prey field of the predator, it will be negatively size-selective. Overall the effect will be size-independent, because each individual has to pass through this period of predation. Since plaice passes completely through the prey field of the predator before the end of June, it is unlikely that the significant differences in population growth between the various meristic subgroups are caused by the effect of sizeselective mortality. Furthermore, in June predation by fishes on plaice starts. At the beginning, this predation is positively size-selective, concentrating on the largest individuals that first enter the prey field of the predator. This means that the significant differences in population growth between the various meristic subgroups is not a bias introduced by (negative) size-selective mortality.

Fig. 9. Pleuronectes platessa. Relationship between number of meristic characteristics and mean growth rate $\left(\mathrm{mm} \mathrm{d}^{-1}\right) \mathrm{dur}$ ing mid April to the end of June for the various subgroups of 0-group plaice at Balgzand in 1995. (a) Vertebrae; (b) anal fin rays; (c) dorsal fin rays. For more information see text
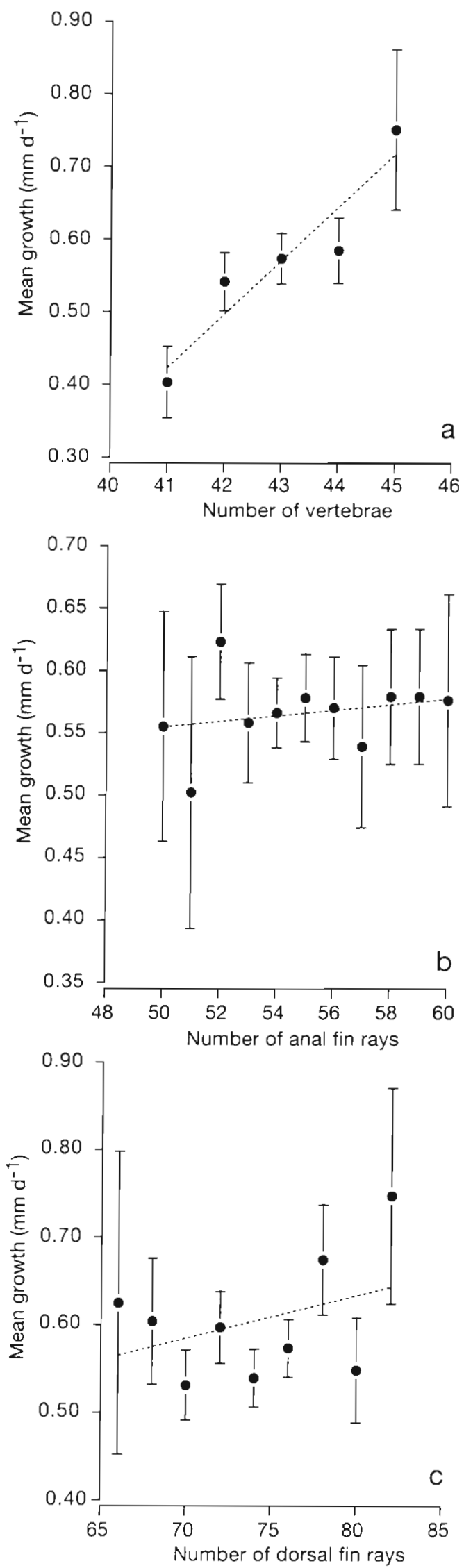


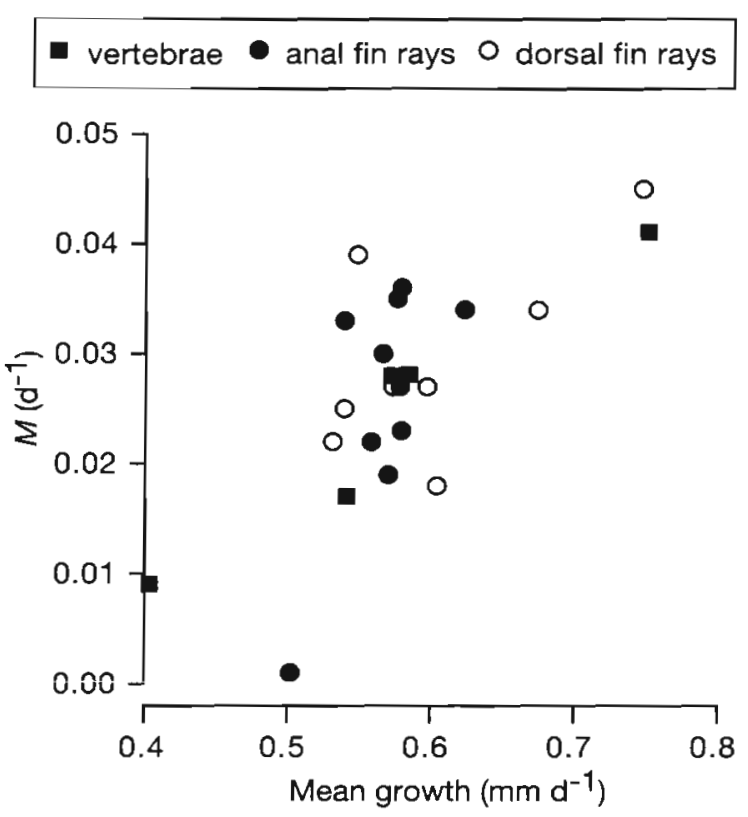

Fig. 10. Pleuronectes platessa. Relationship between mean growth rate $\left(\mathrm{mm} \mathrm{d}^{-1}\right)$ during the period mid April to the end of June and mean instantaneous mortality rate $\left(M, d^{-1}\right)$ for the various subgroups of 0-group plaice at Balgzand in 1995. For more information see text

The positive relationship between mortality and number of vertebrae might suggest selective predation for vertebral number. In the field, such a selective predation has never been observed. However, it has been described for young sticklebacks Gasterosteus aculeatus under laboratory conditions (Swain \& Lindsey 1984). The underlying mechanisms are still unclear. According to Swain \& Lindsey (1984), it might result from a correlation between vertebral number and some important morphological or behavioural characteristic in avoiding predators. In this context, Spouge \& Larkin (1979) suggest that it might be related to locomotory performance. Laboratory observations on stickleback larvae by Swain (1992) indeed showed that burst speed did depend on vertebral phenotype, although within a narrow window of length. Such a direct link between vertebral phenotype and swimming performance of the fish would also explain why no significant, but only a weak relationship, has been found with the number of dorsal and anal fin rays. There is no selection on the numbers of dorsal and anal fin rays but they only co-vary to some extent with the number of vertebrae (see Table 1).

The above evidence suggests that the number of vertebrae is a reflection of the variability induced by environmental conditions during early life, which are still expressed in growth differences later on in juvenile life, and that the number of vertebrae shows a direct positive relationship with mortality.

\section{Irreversible non-genetic adaptation}

The positive correlation between population growth and the number of meristic characteristics appears to be present in both vertebrae, and in anal and dorsal fin rays; however a significant relationship is found only with the number of vertebrae. Since the number of vertebrae appears to be determined by the temperature conditions during the egg stage (Hiddink 1997), this suggests that the non-genetic (temperature) adaptation during the egg stage is more prominent than that later on during the larval stage. Higher temperatures during the egg stage result in a higher number of vertebrae and in a higher growth rate during the juvenile stage. During the growing season of the juveniles at Balgzand, water temperature increased from about $8^{\circ} \mathrm{C}$ in April to about $20^{\circ} \mathrm{C}$ in July. This means that during the growing season temperatures might have been more favourable for those individuals hatched at $10^{\circ} \mathrm{C}$ than those hatched at $8^{\circ} \mathrm{C}$. It provides strong support for Kinne's (1962) 'irreversible non-genetic adaptation' hypothesis, that the variability induced by environmental conditions during early life still expresses itself later on in life. Induced functional non-genetic adaptation during early life is apparently not reversible during the subsequent juvenile life.

These results demonstrate that growth and predation of 0 -group plaice were strongly selective for the number of vertebrae under the environmental conditions at Balgzand, and that the vertebral number appears to be not selectively neutral. Since water temperature conditions during egg drift vary in the Southern Bight of the North Sea over the years (Van der Veer \& Witte 1999), year-to-year variability in vertebral number of the settling larvae might be expected to occur. Similarly, temperature conditions at Balgzand during the growing season of the juveniles also vary (Zijlstra et al 1982, Van der Veer 1986). This implies that the relationship between growth and mortality with vertebral number (positive, neutral or negative) will vary over the years and will depend on the combination of environmental conditions, especially during the egg stage rather than during the subsequent juvenile stage. The observation that the vertebral number is not selectively neutral also has implications in stock enhancement programmes where mass release of small juveniles occurs, as in the case of Japanese flounder Paralichthys olivaceus in Japan (Tanaka et al. 1997). Due to irreversible non-genetic adaptation, temperature conditions experienced during early life will affect and set the temperature preferences and optima later on in life. If egg and larval development in hatcheries occurs at a temperature different from that in the field for the wild population, stock enhancement will also occur with phenotypically different individuals. The 
result will be a selection either in favour of the wild population or in favour of the released individuals depending on the local conditions. This aspect should be carefully considered; otherwise, either the impact of the stock enhancement will not be optimal, or it might even partly overwhelm the already low local wild population.

Acknowledgements. Thanks are due to our colleague Mark Fonds, who initiated this project, to Henk Hobbelink for graphical assistance, to Jaap van der Meer for statistical advice and to Ewout Adriaans, skipper of RV 'Griend' for assistance during the field work. The comments of the anonymous reviewers improved the manuscript considerably. This is NIOZ publication no 3424 .

\section{LITERATURE CITED}

Creutzberg F, Eltink AThGW, Van Noort GJ (1978) The migration of plaice larvae Pleuronectes platessa into the western Wadden Sea, In: McLusky DS, Berry AJ (eds) Physiology and behaviour of marine organisms. Proc 12th Eur Mar Biol Symp. Stirling, Scotland, UK, 5-12, September 1977. Pergamon Press, Oxford, p 243-251

Dannevig A (1950) The influence of the environment on number of vertebrae in plaice. Rep Norw Fish Mar Invest 9:3-6

Dapper R (1978) De Balgzand scholgegevens 1975, 1976. 1977. Neth J Sea Res Int Rep 1978(12), p 1-53

Ellis T (1994) Production and mortality of early life history stages of flatfishes. PhD thesis, University of Liverpool, p 1-239

Harding D, Talbot JW (1973) Recent studies on the eggs and larvae of the plaice (Pleuronectes platessa L.) in the Southern Bight. Rapp PV Réun Cons Int Explor Mer 164: $261-269$

Harding D, Nichols JH, Tungate DS (1978) The spawning of the plaice (Pleuronectes platessa L.) in the southern North Sea and the English Channel. Rapp PV Réun Cons Int Explor Mer 172:102-113

Hiddink JG (1997) Experimental investigations on the effect of temperature on egg production, larval quality and recruitment in flatfish. Neth J Sea Res Int Rep 1997(4): $1-40$

Kinne O (1962) Irreversible nongenetic adaptation. Comp Biochem Physiol 5:265-282

Kuipers BR (1973) On the tidal migration of young plaice (Pleuronectes platessa) in the Wadden Sea. Neth J Sea Res 6:376-388

Kuipers BR (1975) On the efficiency of a two meter beam trawl in juvenile plaice (Pleuronectes platessa L.). Neth $\mathrm{J}$ Sea Res 9:69-85

Lindsey CC (1988) Factors controlling meristic variation. In: Hoar WS, Randell DJ (eds) Fish physiology, Vol. 11B, Academic Press, San Diego, p 197-274

Molander AR, Molander-Swedmark M (1957) Experimental

Editorial responsibility: Otto Kinne (Editor),

Oldendorf/Luhe, Germany investigations on variation in plaice (Pleuronectes platessa Linné). Inst Mar Res Lysekil Ser Biol 7:1-45

Potthoff $T$ (1983) Clearing and staining techniques. Am Soc Ichthyol Herpetol Spec Publ 1:35-37

Riley JD, Corlett $J$ (1966) The numbers of 0-group plaice in Port Erin Bay, 1964-66. Rep Mar Biol Stn Port Erin 781965:51-56

Sumpson AC (1959) The spawning of the plaice (Pleuronectes platessa) in the Irish Sea. Fish Invest Ser II 22(8):1-30

Spouge JL, Larkin PA (1979) A reason for pleomerism. J Fish Res Board Can 36:255-269

Swain DP (1992) The functional basis of natural selection for vertebral traits of larvae in the stickleback Gasterosteus aculeatus. Evolution 46:987-997

Swain DP, Lindsey CC (1984) Selective predation for vertebral number of young sticklebacks, Gasterosteus aculeatus. Can J Fish Aquat Sci 41:1231-1233

Talbot JW (1976) The dispersal of plaice eggs and larvae in the Southern Bight of the North Sea. J Cons Int Explor : ier $37: 221-248$

Talbot JW (1978) Changes in plaice larval dispersal in the last fifteen years. Rapp PV Réun Cons Int Explor Mer 172: $114-123$

Tanaka M. Ohkawa T, Maeda I, Kinoshita I, Seikai T, Nishuda M (1997) Ecological diversities and stock structure of the flounder in the Sea of Japan in relation to stock enhancement. Bull Nat Inst Res Aquacult Suppl 3:77-85

Táning AV (1944) Experiments on meristic and other characteristics in fishes. I. On the influence of temperature on some meristic characteristics in sea-trout and the fixation period of these characteristics. Medd Dan Fisk Havunders Ser Fisk 11:1-66

Van der Veer HW (1986) Immigration, settlement and density-dependent mortality of a larval and early post-larval 0-group plaice Pleuronectes platessa population in the western Dutch Wadden Sea. Mar Ecol Prog Ser 29: $223-236$

Van der Veer HW, Bergman MJN (1987) Predation by crustaceans on a newly settled 0 -group plaice Pleuronectes platessa population in the western Wadden Sea. Mar Ecol Prog Ser 35:203-215

Van der Veer HW, Witte JIJ (1999) Year-class strength of plaice Pleuronectes platessa L. in the Southern Bight of the North Sea: a validation and analysis of the inverse relationship with winter seawater temperature. Mar Ecol Prog Ser 184:245-257

Van der Veer HW, Ellis T, Miller JM, Pihl L, Rijnsdorp AD (1997) Size-selective predation on juvenile North Sea flatfish and possible implications for recruitment. In: Chambers RC. Trippel EA (eds) Early life history and recruitment in fish populations. Chapman \& Hall, London, p 279-303

Wilkinson L (1989) SYSTAT: the system for statistics. SYSTAT Inc, Evanston, IL, p 1-368

Zijlstra JJ, Dapper R, Witte JIJ (1982) Settlement, growth and mortality of post-larval plaice (Pleuronectes platessa L.) in the western Wadden Sea. Neth J Sea Res 15:250-272

Submitted: June 11, 1999; Accepted: October 22, 1999

Proofs received from author(s): April 13, 2000 